\title{
PACIENTE JOVEN CON CARCINOMA DE MERKEL PALPEBRAL: MICROCIRUGÍA DE MOHS VERSUS EXENTERACIÓN
}

\author{
YOUNG PATIENT WITH EYELID MERKEL CARCINOMA: \\ MOHS MICROSURGERY VERSUS EXENTERATION
}

\author{
RODRÍGUEZ-PRIETO MA ${ }^{1}$, ALONSO-ALONSO T ${ }^{1}$, TORIBIO-GARCÍA JA², \\ MATEOS-HERNÁNDEZ A ${ }^{2}$
}

\begin{abstract}
RESUMEN
Caso clínico: Se presenta el caso de una paciente de 47 años afecta de progeria que después de tratamiento con ciclosporina por trasplante corneal presentó carcinoma de Merkel (MCC) palpebral. Tras exéresis completa mediante cirugía de Mohs (MMS) y tratamiento adyuvante con radioterapia, recidivó y fue necesario realizar exenteración orbitaria. La paciente se encuentra asintomática tras 24 meses de seguimiento.

Discusión: $\mathrm{El} \mathrm{MCC}$ es un tumor agresivo con mayor incidencia en ancianos, mujeres e inmunodeprimidos. Nuestra visión del enfermo debe ser global evitando añadir factores de riesgo a pacientes ya predispuestos. La MMS parece desaconsejada en el tratamiento del MCC, debiendo realizar una excisión radical si se produce recidiva.

Palabras clave: Carcinoma de Merkel, microcirugía de Mohs, tumor palpebral, exenteración orbitaria, ciclosporina, paciente joven.
\end{abstract}

\begin{abstract}
Case report: We present the case of a 47-year-old female suffering from progeria who developed an eyelid Merkel cell carcinoma (MCC) following cyclosporine treatment for a corneal transplant. She underwent excision of the lesion by Mohs micrographic surgery (MMS) and received adjuvant treatment with radiotherapy. Later she had a recurrent tumour for which a wide excision with orbital exenteration was performed. The patient was fit and well at the 24-month follow-up.

Discussion: MCC is an aggressive tumour that has a larger incidence in elderly people, women and immunosuppressed patients. Our approach with the patient must be global, avoiding risk factors in predisposed subjects. MMS seems unsuitable for the treatment of MCC; if tumour recurrence occurs a wide resection should be performed (Arch Soc Esp Oftalmol 2009; 84: 581-584).
\end{abstract}

Key words: Merkel cell carcinoma, Mohs microsurgery, eyelid tumour, orbital exenteration, cyclosporine, young patient.

\footnotetext{
Recibido: 18/8/08. Aceptado: 5/11/09.

Hospital de León. León. España.

${ }^{1}$ Licenciado en Medicina. Servicio de Dermatología.

${ }^{2}$ Licenciado en Medicina. Servicio de Oftalmología.

Comunicación presentada en el XVIII Congreso de la Sociedad Española de Cirugía Plástica Ocular y Orbitaria (Valladolid 2008).

Correspondencia:

J. Álvaro Toribio García

Avda. Compostilla, $24,3 .^{\circ} \mathrm{B}$

24400 Ponferrada (León)

España

E-mail: draltor@gmail.com
} 


\section{INTRODUCCIÓN}

El carcinoma de células de Merkel (MCC) es una neoplasia cutánea altamente invasiva. En su tratamiento se ha propuesto la excisión local con márgenes amplios, la cirugía micrográfica de Mohs

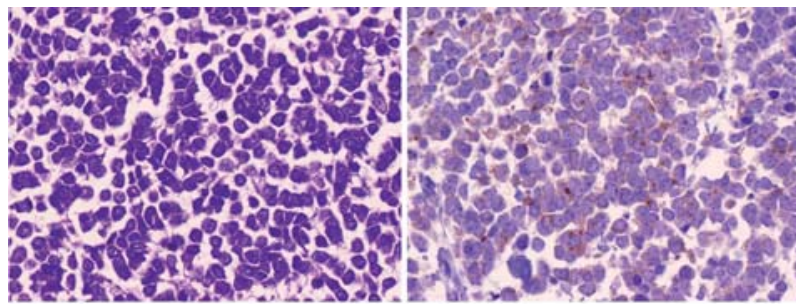

(A)

(B)

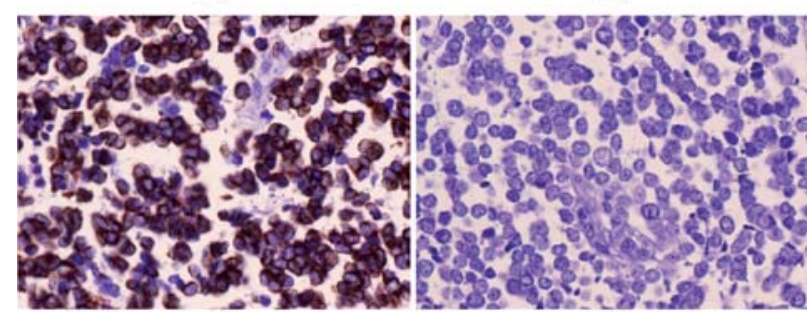

(C)

(D)

Fig. 1: (A) Pequeñas células basofílicas con alto índice mitótico (hematoxilina-eosina, 400X). (B) Inmunotinción mostrando positividad a la cromogranina, típica de tumores neuroendocrinos (400X). El MCC se reconoce por la inmunotinción citoqueratina-20 positiva con patrón granular citoplasmático $(C)$ y negatividad a la citoqueratina-7(D).

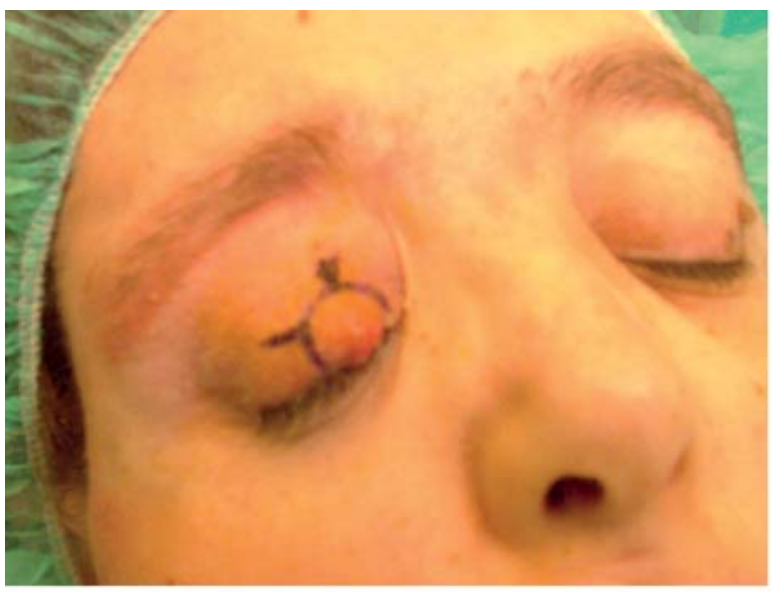

(A)
(MMS) con o sin radioterapia, y la excisión radical con exenteración orbitaria (1).

\section{CASO CLÍNICO}

Mujer caucásica de 47 años afecta de progeria con malformaciones óseas (pectus excavatum, hipoplasia de huesos malares y arcos cigomáticos), malformaciones viscerales (hepatomegalia, dilatación de la pelvis renal izquierda), anemia ferropénica, insuficiencia venosa, antecedentes de erisipela y de sarcoma de Kaposi clásico en tercio distal de ambas extremidades inferiores tratado con interferón diez años atrás. Había sido intervenida de implante de prótesis para huesos malares, mamoplastia, varios legrados endometriales y apendicectomía. Sus padres eran primos-hermanos. A nivel ocular, presentaba miopía magna, intervención de cataratas en ambos ojos, intervención de pterigium en ojo derecho en dos ocasiones con leucoma corneal residual por lo que se realizó queratoplastia penetrante en 2002. El tejido fue rechazado y se decidió iniciar inmunosupresión con ciclosporina recibiendo un nuevo trasplante corneal. En el centro donde se realizaron los transplantes se biopsió a finales de 2005 una lesión nodular, violácea, de $7 \mathrm{~mm}$ en párpado superior derecho, que había aparecido 3 meses antes y en los últimos dos meses había crecido bruscamente. Se informó como MCC (fig. 1), momento en que remitieron a la paciente a nuestro hospital.

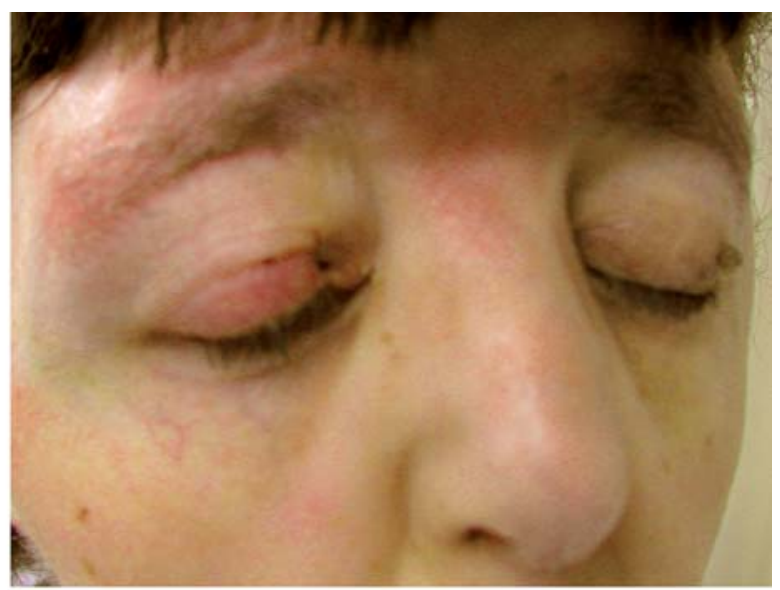

(B)

Fig. 2: (A) Aspecto previo a la extirpación mediante MMS. (B) Aspecto postoperatorio a la semana de la MMS. 
El examen de la totalidad de la piel corporal, la palpación de cadenas ganglionares y la tomografía axial computerizada (TAC) cráneo-tóraco-abdominal fueron normales, por lo que se clasificó el tumor como enfermedad localizada.

En diciembre de 2005 se realizó extirpación del tumor mediante MMS en dos etapas (fig. 2). La linfografía produjo una captación difusa de toda la cadena ganglionar latero-cervical que contraindicaba la realización del ganglio centinela. Se realizó tratamiento con radioterapia sobre el lecho del tumor primario y cadenas ganglionares latero-cervicales derechas con 50 Gy dosis total. Cuatro meses más tarde aparecieron 3 nódulos duros de $2 \mathrm{~cm}$ cada uno (fig. 3A), localizados en párpado superior e inferior derechos y región temporal del mismo lado, que tras biopsia se informaron como MCC.

Se decidió intervenir mediante una exenteración orbitaria derecha ampliada a región temporal homolateral dejando unos márgenes de $2,5 \mathrm{~cm}$ respecto a las lesiones (fig. 3B). Se cubrió la órbita mediante un colgajo miocutáneo de rotación frontotemporal (figs. 3C y 3D) y el defecto restante con un injerto de piel total obtenida de la región supraclavicular izquierda (figs. $3 \mathrm{E}$ y $3 \mathrm{~F}$ ). En el postoperatorio inmediato no presentó complicaciones (fig. 4).

Los controles posteriores fueron negativos, y tras 24 meses de seguimiento no se ha producido recidiva (fig. 5).

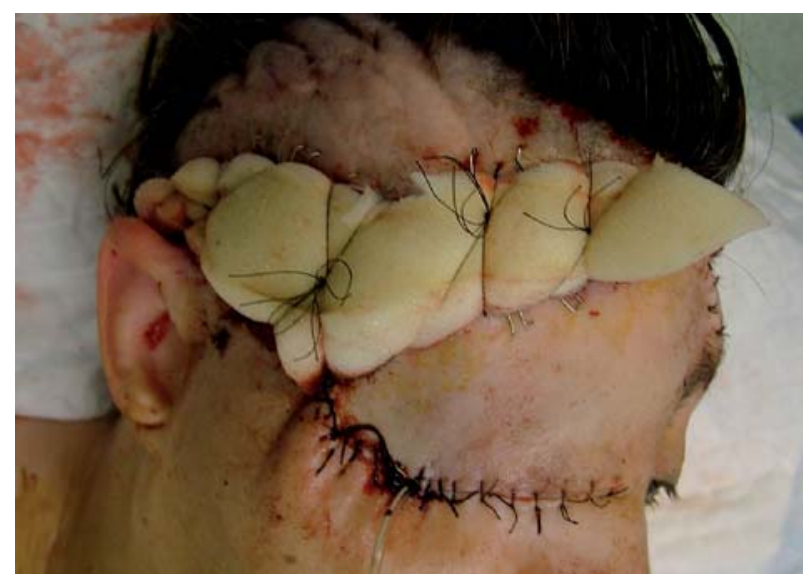

Fig. 4: Aspecto postoperatorio a las 24 horas de la exenteración orbitaria ampliada. El injerto cutáneo queda oculto bajo la almohadilla.

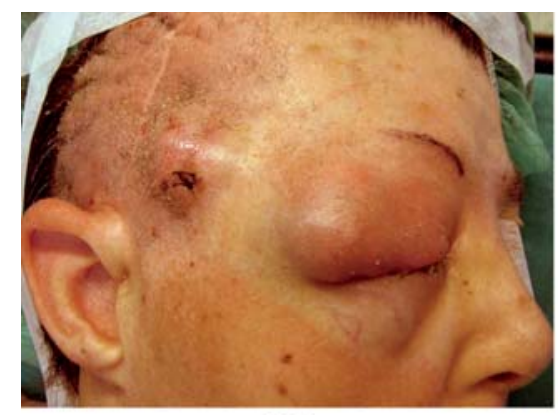

(A)

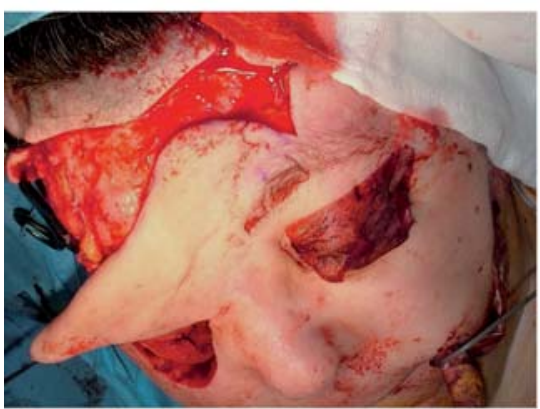

(D)

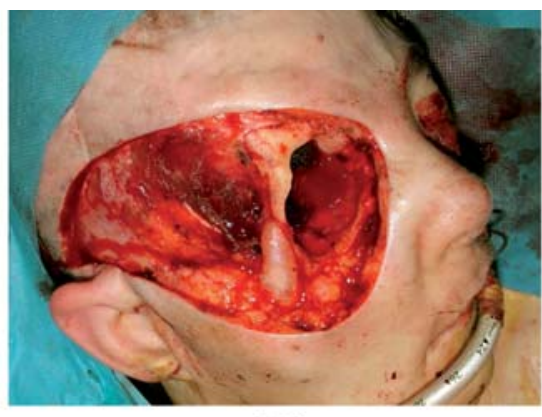

(B)

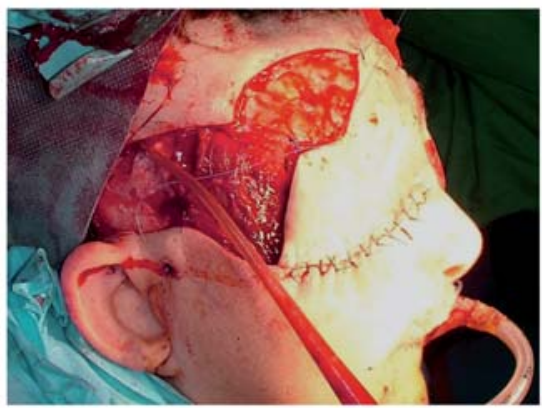

(E)

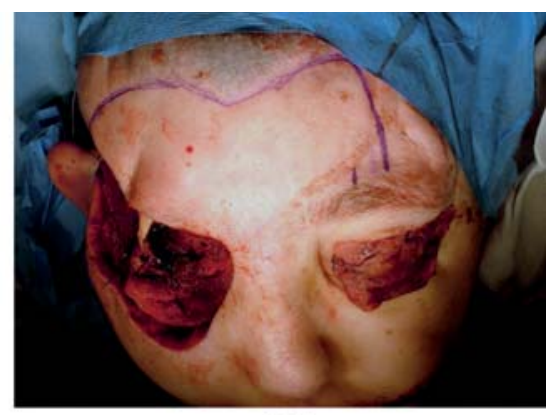

(C)

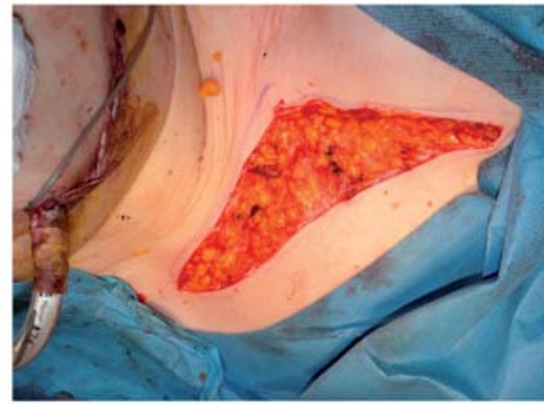

(F)

Fig. 3: (A) Recurrencia local en párpados y región temporal derecha. (B) Exenteración orbitaria ampliada a región temporal. (C) Diseño del colgajo miocutáneo frontal. (D) Rotación del colgajo cubriendo la órbita. (E) Defecto en región fronto-temporal que se solucionó con un injerto de piel de región supraclavicular izquierda $(F)$. 


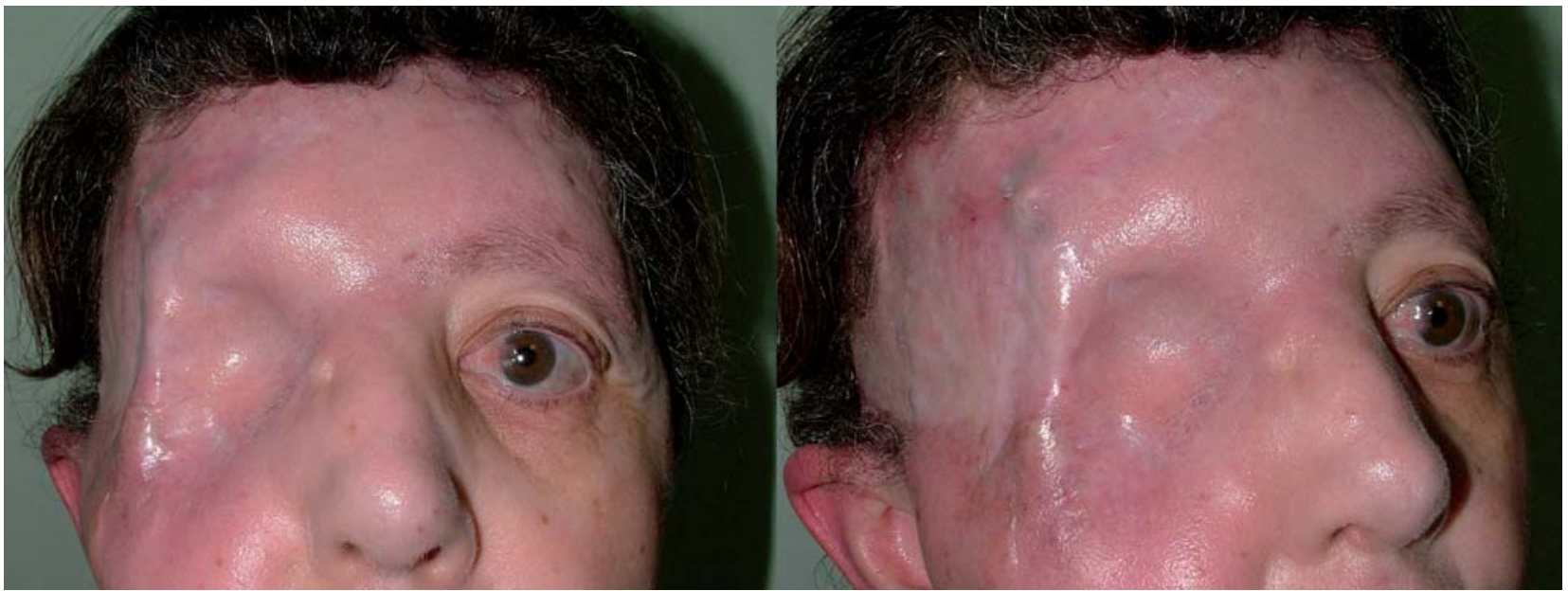

Fig. 5: Aspecto postoperatorio tardío a los 6 meses.

\section{DISCUSIÓN}

El MCC es una rara neoplasia neuroendocrina de la piel descrita por primera vez en 1972 por Toker $(1,2)$. Típicamente aparece en pacientes mayores [el $75 \%$ tienen 65 o más años (2)], aunque también se ha descrito en adultos jóvenes con síndromes de displasia ectodérmica congénita (1). Su incidencia está incrementada en áreas de exposición solar y después de inmunosupresión y trasplantes de órganos (2). Es más frecuente en población blanca y dos veces más frecuente en mujeres (3). La mitad de los MCC ocurren en la región de cabeza y cuello, y una décima parte en los párpados o región periocular con preferencia por el párpado superior $(1,3)$.

Presentamos una paciente con un síndrome polimalformativo y envejecimiento precoz constatado por la presencia de cataratas, pterigium y Sarcoma de Kaposi. En este contexto debería haberse evitado la terapia con ciclosporina en un paciente ya inmunodeprimido. No podemos afirmar que la aparición del MCC haya sido consecuencia de este tratamiento, pero el antecedente de sarcoma de Kaposi es una clara contraindicación para esta medicación. Esto debe hacernos recordar que tenemos que estudiar al paciente globalmente y no sólo desde nuestra especialidad.

El comportamiento del MCC es agresivo con una alta incidencia de recurrencia local (30\% a un año), invasión linfática (50-60\% de los casos) y metástasis (más del 30\% de los casos) $(1,2)$. La supervivencia a 5 años para el MCC cutáneo es del $38 \%(1,2)$, aunque se ha descrito algún caso de regresión espontánea (2).
El tratamiento del MCC localizado es quirúrgico, habiéndose propuesto cirugía con márgenes amplios de 2,5 cm (3). La MMS permite respetar la mayor cantidad de tejido posible ya que estudia intraoperatoriamente todos los bordes del tumor (4), sin embargo esta técnica no parece adecuada en el tratamiento del carcinoma de Merkel aunque se ha publicado algún caso de curación (5). En otros estudios se indica que los cortes en frío no permiten el estudio adecuado de estas células tumorales (2) y aunque la cirugía de Mohs asociada a radioterapia parece presentar mejores resultados (5), no la consideramos una técnica adecuada en este tumor. Ante la recidiva local en el MCC debemos realizar una cirugía radical, ya que la curación es posible (2).

La exenteración orbitaria y reconstrucción con colgajo miocutáneo frontotemporal es una técnica sencilla que permite vascularizar la cavidad anoftálmica con un espesor fino que facilita la detección de recidivas y consigue un resultado estético aceptable.

\section{BIBLIOGRAFÍA}

1. Ratner D, Nelson BR, Brown MD, Johnson TM. Merkel cell carcinoma. J Am Acad Dermatol 1993; 29: 143-156.

2. Saadi AK, Danks JJ, Cree IA, Collin JR. Merkel cell tumour: case reports and review. Orbit 1999; 18: 45-52.

3. Kivelä T, Tarkkanen A. The Merkel cell and associated neoplasms in the eyelids and periocular region. Surv Ophthalmol 1990; 35: 171-187.

4. Finley EM. The Principles of Mohs Micrographic Surgery for Cutaneous Neoplasia. The Ochsner Journal 2003; 5: 22-33.

5. Pathai S, Barlow R, Williams G, Olver J. Mohs' micrographic surgery for Merkel cell carcinomas of the eyelid. Orbit 2005; 24: 273-275. 